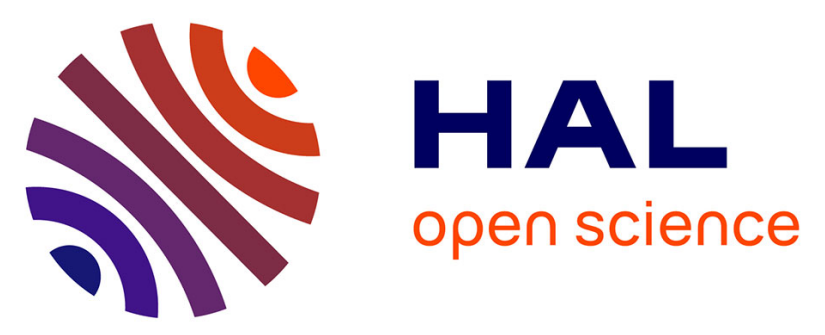

\title{
FKBP12.6 binding of ryanodine receptors carrying mutations associated with arrhythmogenic cardiac disease
}

Spyros Zissimopoulos, N. Lowri Thomas, Wan Jamaluddin, F. Anthony Lai

\section{- To cite this version:}

Spyros Zissimopoulos, N. Lowri Thomas, Wan Jamaluddin, F. Anthony Lai. FKBP12.6 binding of ryanodine receptors carrying mutations associated with arrhythmogenic cardiac disease. Biochemical Journal, 2009, 419 (2), pp.273-278. 10.1042/BJ20082324 . hal-00479135

\section{HAL Id: hal-00479135 \\ https://hal.science/hal-00479135}

Submitted on 30 Apr 2010

HAL is a multi-disciplinary open access archive for the deposit and dissemination of scientific research documents, whether they are published or not. The documents may come from teaching and research institutions in France or abroad, or from public or private research centers.
L'archive ouverte pluridisciplinaire HAL, est destinée au dépôt et à la diffusion de documents scientifiques de niveau recherche, publiés ou non, émanant des établissements d'enseignement et de recherche français ou étrangers, des laboratoires publics ou privés. 
FKBP12.6 binding of ryanodine receptors carrying mutations associated with arrhythmogenic cardiac disease

Spyros Zissimopoulos, N. Lowri Thomas, Wan W. Jamaluddin and F. Anthony Lai

Wales Heart Research Institute

Department of Medicine - Cardiology

Cardiff University School of Medicine

Cardiff CF14 4XN

UK

Correspondence to S Zissimopoulos;

Tel: +44-29-20744519; FAX: +44-29-20743500;

Email: zissimopouloss@cf.ac.uk

Short title: Immunophilin binding of RyR2 mutants linked to cardiac sudden death

Keywords: Arrhythmogenic cardiac disease, ryanodine receptor, immunophilin, redox regulation, protein interaction

\section{Synopsis}

In this communication, we show that distinct human RyR2 inherited mutations expressed in mammalian cells exhibit either unaltered or increased FKBP12.6 binding compared to wild-type. Oxidising conditions result in reduced FKBP12.6 binding, but to the same extent as for wild-type. Our findings suggest that FKBP12.6 regulation of RyR2 is unlikely to be the primary defect in inherited arrhythmogenic cardiac disease.

\section{Introduction}

Catecholaminergic polymorphic ventricular tachycardia (CPVT) is an inherited arrhythmogenic disease characterised by adrenergically-mediated, bi-directional or polymorphic ventricular tachycardia leading to syncope and/or sudden cardiac death [1, 2]. CPVT is a highly malignant disease (mortality rates of 30-35\%) with incomplete penetrance, manifesting in childhood and adolescence. Patients with CPVT have structurally normal hearts and typically present with ventricular arrhythmias due to physical or emotional stress. Arrhythmogenic right ventricular dysplasia type 2 (ARVD2) is a related disease with mild structural abnormalities of the right ventricular myocardium in addition to stress-induced polymorphic ventricular tachycardia. CPVT and ARVD2 have been linked with mutations in 
ryanodine receptor type 2 (RyR2), the intracellular channel mediating the rapid $\mathrm{Ca}^{2+}$ release from the sarcoplasmic reticulum (SR) that triggers cardiac muscle contraction [3].

RyR2 forms a complex with a small accessory protein, the 12.6kDa FK506-binding protein (FKBP12.6) that stabilises channel conductance and facilitates channel closure [3]. Defective regulation of RyR2-FKBP12.6 association has been suggested to play a role in the pathogenesis of acquired and inherited cardiac disease. Marks and colleagues proposed that PKA-mediated "hyper-phosphorylation" of RyR2, resulting in dissociation of FKBP12.6, underlies the abnormal diastolic SR $\mathrm{Ca}^{2+}$ release during $\beta$-adrenergic stimulation [4-7]. This proposal was based on their observation that mutant RyR2 channels had reduced affinity for FKBP12.6, and that mice haploinsufficient for FKBP12.6 displayed exercise-induced ventricular arrhythmias, which were prevented by $\beta$-adrenergic blockers or JTV519, a drug that restored the RyR2-FKBP12.6 association. However, these results are not consistent with those of other laboratories [8-12].

The RyR2 "hyper-phosphorylation” hypothesis with ensuing loss of FKBP12.6 is an attractive mechanism that predicts an increased diastolic $\mathrm{Ca}^{2+}$ release leading to delayed afterdepolarisations, the underlying cause of cardiac arrhythmias in heart failure and sudden cardiac death. However, FKBP12.6 dissociation from RyR2 may also result from a different causal mechanism. For example, we have recently demonstrated that oxidised RyR2 has a reduced affinity for FKBP12.6 [13]. Thus, in the present study we have assessed the FKBP12.6 interaction with recombinant wild-type and mutant RyR2 channels (R176Q, S2246L and R4497C) under reducing and oxidising conditions, to determine if a redox mechanism may play a role in RyR2 disease pathogenesis. R176Q was initially associated with ARVD2 [14], while S2246L and R4497C were causative of CPVT [15]. All three mutations have been previously characterised in in vitro systems and channel dysfunction has been correlated with both FKBP12.6-dependent and-independent mechanisms [4, 8, 9, 16].

\section{Methods}

Cell culture reagents were from Invitrogen. In vitro protein expression system was from Promega (TNT T7 Quick-coupled transcription and translation). Radioactive sulphur (Pro-Mix, GE Healthcare) contained $\sim 70 \%$ L- $\left[{ }^{35}\right.$ S $]$ methionine and $30 \%$ L- $\left[{ }^{35}\right.$ S $]$ cysteine. Electrophoresis reagents were from Bio-Rad. CHAPS and rapamycin were from Calbiochem, whereas all other reagents were from Sigma. Redox reagents were prepared as 100x stock solutions, aliquoted and stored frozen $\left(-80^{\circ} \mathrm{C}\right) . \mathrm{H}_{2} \mathrm{O}_{2}$ was always added fresh from $30 \%$ aqueous solution $\left(4^{\circ} \mathrm{C}\right)$. Cell-free protein expression, SDS-PAGE, autoradiography, Western blot and densitometry analysis was carried out as described previously [13]. Statistical analysis of densitometric data was performed using unpaired Student's t-test.

\section{Plasmid construction}

Preparation of plasmids expressing eGFP-tagged human RyR2 mutants R176Q, S2246L and R4497C have been described previously [8, 16]. Untagged versions were prepared by replacing the MluI-SpeI $\sim 1$.3kb fragment (containing part of the CMV promoter and the entire eGFP sequence) with a PCR-generated MluI-SpeI $\sim 0.6 \mathrm{~kb}$ fragment recreating the CMV promoter, but without the eGFP, using oligonucleotide primers; forward: GCACGCGTGTTCATAGCCCATATATGGAG, reverse: GGCGACTAGTAGCGCTAGCGGATCTGAC. Untagged channels were produced in order to avoid potential redox-related problems with the eGFP moiety.

\section{Cell Culture, Transfection and Microsome Preparation}

HEK293 cells were cultured in DMEM medium supplemented with $10 \%$ foetal bovine serum and $2 \mathrm{mM}$ glutamine, in a humidified atmosphere of $5 \% \mathrm{CO}_{2}$ at $37^{\circ} \mathrm{C}$. Cells at $\sim 70 \%$ confluence were transiently transfected with $24 \mu \mathrm{g}$ of RyR2 plasmid DNA per $100 \mathrm{~mm}$ Petri 
dish using the calcium phosphate precipitation method. Cells were harvested 24hr posttransfection and crude microsomes were prepared as described below. To obtain similar protein levels for RyR2 wild-type and mutants, equal numbers of cells were simultaneously transfected and processed for all four RyR2 constructs.

Crude microsomes were prepared as follows: HEK293 cells were resuspended in homogenisation buffer ( $0.3 \mathrm{M}$ sucrose, $5 \mathrm{mM}$ Hepes, $\mathrm{pH} 7.4), \sim 15 \times 10^{6}$ cells $/ \mathrm{ml}$ of buffer, supplemented with protease inhibitors (Complete; Roche), and homogenised on ice by 20 passages through a needle (23G, $0.6 \times 25 \mathrm{~mm})$ and dispersing the cell suspension through a half volume of glass beads (425-600microns, Sigma). Cell nuclei and glass beads were removed by centrifugation at $1,500 \mathrm{~g}$ for $5 \mathrm{~min}$ at $4^{\circ} \mathrm{C}$; the supernatant was subjected to centrifugation at $10,000 \mathrm{~g}$ for $10 \mathrm{~min}$ at $4^{\circ} \mathrm{C}$ and the supernatant saved. Microsomal membranes were pelleted at $\sim 100,000 \mathrm{~g}$ (50,000rpm, Beckman TLA100.4 rotor) for $1 \mathrm{hr}$ at $4^{\circ} \mathrm{C}$, resuspended in homogenisation buffer and stored at $-80^{\circ} \mathrm{C}$.

\section{Co-Immunoprecipitation Assays}

RyR2 protein levels were assessed by Western blot analysis of microsomes from transfected HEK293 cells using antibodies directed against different epitopes, followed by densitometry analysis. In order to ensure identical protein amounts for wild-type and mutant RyR2, 500 $\mu$ g of microsomes expressing the least abundant RyR2 construct was processed in co-IP assays. Lower amounts of microsomes were processed for the other constructs to obtain equivalent RyR2 content, as assessed by RyR2 immunoblot densitometry. The total protein content was subsequently adjusted to $500 \mu \mathrm{g}$ for all constructs with microsomes prepared from untransfected cells.

In order to assess the phosphorylation level of the expressed wild-type and mutant RyR2 proteins, an anti- phosphoserine antibody (16B4; Calbiochem) was used in immunoblots that were loaded with uniform total RyR2 content. There was equivalent, very low level phosphorylation of RyR2 detected using this antibody (see Supplemental Figure), consistent with previous studies using HEK293 cells where exogenous PKA was required to phosphorylate the expressed RyR2 [4].

HEK293 microsomes $(500 \mu \mathrm{g})$ were solubilised in $200 \mu \mathrm{l}$ of IP buffer (20mM Tris, $150 \mathrm{mM} \mathrm{NaCl}, 0.4 \%$ CHAPS, $\mathrm{pH} 7.4$, and Complete protease inhibitors) by overnight incubation at $4^{\circ} \mathrm{C}$ with continuous mixing. Insoluble material was pelleted at $20,000 \mathrm{~g}$ for $10 \mathrm{~min}$ at $4^{\circ} \mathrm{C}$ and the supernatant was treated with an appropriate redox reagent (2mM DTT, $1 \mathrm{mM} \mathrm{H} \mathrm{H}_{2}, 200 \mu \mathrm{M}$ diamide) for $30 \mathrm{~min}$ at room temperature. In vitro synthesised, haemoglobin-free, radiolabelled FKBP12.6 was added and incubated for $1 \mathrm{hr}$ at $4^{\circ} \mathrm{C}$. The RyR2-specific $\mathrm{Ab}^{1093}$ was added at 1:40 dilution and the sample was incubated for $2 \mathrm{hr}$ at $4^{\circ} \mathrm{C}$, followed by addition of $20 \mu \mathrm{l}$ of Protein G Dynabeads (Dynal) and incubation for a further $2 \mathrm{hr}$ with continuous mixing. Protein immunocomplexes were isolated with the use of a magnetic particle concentrator (MPC-S, Dynal), and beads were washed three times with IP buffer. Immunoprecipitated proteins were resuspended in SDS-PAGE loading buffer (60mM Tris, $2 \%$ SDS, $10 \%$ glycerol, 5mM EDTA, 2\% $\beta$-mercaptoethanol, $0.01 \%$ bromophenol blue, $\mathrm{pH}$ 6.8), heated at $85^{\circ} \mathrm{C}$ for $5 \mathrm{~min}$, and analysed by SDS-PAGE and autoradiography.

\section{Results}

We initially determined the relative FKBP12.6 binding affinity of recombinant wildtype and mutant RyR2 (R176Q, S2246L and R4497C) by co-immunoprecipitation assays using solubilised HEK293 microsomes, normalised for RyR2 and total protein content as detailed in Methods, incubated with $\left[{ }^{35}\right.$ S]FKBP12.6. Parallel negative controls were processed in the presence of $20 \mu \mathrm{M}$ rapamycin, a specific inhibitor of RyR2-FKBP12.6 interaction. RyR2 was immunoprecipitated with the RyR2 isoform-specific $\mathrm{Ab}^{1093}$ and the presence of coprecipitated $\left[{ }^{35} \mathrm{~S}\right] \mathrm{FKBP} 12.6$ was analysed by SDS-PAGE and autoradiography. As shown in 
Figure 1A, all RyR2 constructs displayed rapamycin-sensitive FKBP12.6 binding. Densitometry analysis and normalisation with wild-type RyR2 revealed that the R176Q mutant binds $\sim 40 \%$ more FKBP12.6 than wild-type under identical conditions (Figure 1D \& Table 1). S2246L also displayed $20 \%$ higher binding, whereas FKBP12.6 interaction of R4497C and wild-type RyR2 were similar. Western blot analysis indicated that equal amounts of wild-type and mutant RyR2 channels were recovered in the immunoprecipitate (Figure 1C). To compare whether channel activity affects the RyR2-FKBP12.6 interaction, we also conducted co-IP experiments in the presence of $2 \mathrm{mM} \mathrm{MgCl}_{2}$ that should result in channels in their closed state (Figure 1B). No effect was apparent, as the results with $\mathrm{MgCl}_{2}$ were similar to those obtained under ambient conditions (Figure 1E \& Table 1).

To address the redox sensitivity of RyR2-FKBP12.6 interaction, we treated the solubilised HEK293 microsomes with redox reagent (2mM DTT, $1 \mathrm{mM} \mathrm{H}_{2} \mathrm{O}_{2}$, or $200 \mu \mathrm{M}$ diamide) for $30 \mathrm{~min}$ at room temperature followed by incubation with [ $\left.{ }^{35} \mathrm{~S}\right] \mathrm{FKBP} 12.6$. RyR2 was immunoprecipitated with $\mathrm{Ab}^{1093}$ as above and $\left[{ }^{35} \mathrm{~S}\right] \mathrm{FKBP} 12.6$ levels quantitated by autoradiography. Representative autoradiograms are shown in Figure 2A\&B and cumulative data, where results are normalised for the control condition (no redox treatment), are presented in Figure 2E \& Table 2. The sulphydryl-oxidising agents $\mathrm{H}_{2} \mathrm{O}_{2}$ and diamide decreased FKBP12.6 binding to wild-type RyR2 by $\sim 10 \%$ and by $\sim 50 \%$ respectively. This is consistent with results obtained for native RyR2 from pig heart [13], although the $\mathrm{H}_{2} \mathrm{O}_{2}$ effect is less pronounced for the recombinant protein. However, in contrast with the native protein where there was largely no effect, the reducing agent DTT decreased FKBP12.6 binding to recombinant RyR2 by 20\% compared to control.

The effect of $\mathrm{H}_{2} \mathrm{O}_{2}$ and diamide on FKBP12.6 interaction with the three RyR2 mutants (R176Q, S2246L and R4497C) was similar to wild-type, i.e. they decreased FKBP12.6 binding to the same extent as for wild-type (Figure 2E \& Table 2). These results suggest that the point mutations studied here do not alter the diminished FKBP12.6 binding affinity of oxidised RyR2. We also examined whether the closed state recombinant RyR2 affects the redox sensitivity of the FKBP12.6 interaction, since it was previously found that $\mathrm{H}_{2} \mathrm{O}_{2}$ has a less pronounced effect on the native channel in its closed configuration [13]. Thus, we carried out co-IP assays in the presence of $2 \mathrm{mM} \mathrm{MgCl}_{2}$ to promote a closed RyR2 channel (Figure 2C\&D). The results, summarised in Figure $2 \mathrm{~F} \&$ Table 2, are similar to those obtained under ambient conditions indicating absence of significant effect of channel activity on the interaction with FKBP12.6.

\section{Discussion}

RyR2 mutations predispose affected individuals to cardiac arrhythmias, but present a malignant phenotype only following exercise or emotional stress, indicating the requirement for an additional precipitating factor [1, 2]. RyR2-associated cardiac disease is also characterised by incomplete penetrance since some family gene carriers lead a normal life, apparently able to tolerate the elusive precipitating factor. This "trigger" factor could be reactive oxygen species produced in muscles during exercise [17], suggesting that unaffected individuals may possess an enhanced antioxidant defence system. Notably, increased catecholamine levels following sympathetic nervous system activation can lead to cardiomyopathy through the production of reactive oxygen species due to catecholamine autooxidation $[18,19]$.

In the present study, we tested the hypothesis that RyR2 mutants have an increased sensitivity to oxidative conditions compared to wild-type that leads to a more pronounced dissociation of the RyR2-stabilising FKBP12.6 subunit. This could be either due to decreased FKBP12.6 affinity of RyR2 mutants even at rest, or due to oxidation-induced reduction in affinity for FKBP12.6. We chose to study three mutants, R176Q, S2246L and R4497C, representing one from each of the three mutational loci because they are the most studied mutants and knock-in animal models are available [1-3]. The recombinant channels were 
expressed in HEK293 cells, a cell line that has undetectable levels of both RyR [16, 20, 21] and FKBP12.6 proteins [12, 22, 23].

Our results suggest that the impact of the RyR2 point mutations on the interaction with FKBP12.6 is domain- and/or residue-specific. While the RyR2 C-terminal located R4497C mutation did not affect FKBP12.6 affinity, the N-terminal R176Q and central domain S2246L mutants displayed enhanced binding to FKBP12.6 by $\sim 40 \%$ and $\sim 20 \%$ respectively (Figure $1 \mathrm{D}, \mathrm{E} \&$ Table 1). The latter result is unexpected since previous studies have either reported reduced $[4,6]$ or no change in FKBP12.6 binding [8, 9]. It has been suggested that RyR2 mutants show reduced affinity for FKBP12.6 only at sub-saturating FKBP12.6 concentrations with no difference on maximal binding at saturating concentrations [4, 6]. Clearly, we have not reached maximal binding in our co-immunoprecipitation experiments since we find increased rather than unaltered FKBP12.6 binding at least for two of the three mutants tested. The reasons for the disparate results presumably arise from the differences in experimental conditions. For example, Marks and colleagues, who reported reduced affinity for FKBP12.6 by RyR2 mutants, assessed binding levels by measuring the amount of exogenous radiolabelled FKBP12.6 co-sedimenting with RyR2-expressing HEK293 microsomes [4, 6]. However, it should be noted that measurable amounts of FKBP12.6 co-sediment with HEK293 microsomes non-specifically, as observed with untransfected cells [23]. Further, the above authors also used $\left[{ }^{3} \mathrm{H}\right]$ ryanodine binding to quantify RyR2 expression levels $[4,6]$, an assay measuring active channels rather than total number. Due to the higher $\left[{ }^{3} \mathrm{H}\right]$ ryanodine binding activity of RyR2 mutants, however, this may result in overestimation of the mutant RyR2 expressed in HEK293 microsomes.

In the present study, FKBP12.6 binding was assessed by co-immunoprecipitating RyR2 specifically from CHAPS-solubilised HEK293 microsomes pre-incubated with exogenous $\left[{ }^{35} \mathrm{~S}\right] \mathrm{FKBP} 12.6$. Importantly, we paid particular attention, through extensive Western blot and densitometric analysis of RyR2-expressing microsomes, to ensure that identical quantities of RyR2 and total microsomal protein were processed in our co-IP assays. Indeed, equal amounts of wild-type and mutant RyR2 channels were recovered in the immunoprecipitated samples (Figure 1C). Interestingly, slightly higher FKBP levels associated with heart SR were reported for the R4497C knock-in mouse, although this could be due to higher levels expressed in the transgenic animal heart [11]. The R176Q knock-in mouse has also been generated but the RyR2-FKBP12.6 interaction has not been reported [24].

The redox sensitivity of FKBP12.6 interaction with recombinant wild-type RyR2 expressed in HEK293 cells wass similar, but not identical, to the native protein from pig heart (Figure 2E, F \& Table 2). FKBP12.6 binding decreased by 50\% in diamide-treated RyR2, comparable to results obtained for the native protein [13]. The effect of the less potent and more hydrophilic oxidising reagent, $\mathrm{H}_{2} \mathrm{O}_{2}$, on recombinant and native RyR2 was to decrease FKBP12.6 binding by $\sim 10 \%$ and $\sim 25 \%$, respectively [13]. In contrast, the reducing agent DTT diminished FKBP12.6 binding by $20 \%$ for recombinant RyR2, whereas for the native protein it was without effect [13]. It appears that certain accessible cysteine(s) that are oxidised in RyR2 expressed in HEK293 cells, can be effectively reduced by DTT and this affects the binding of FKBP12.6. This is likely due either to the different redox environment of HEK293 cells in culture versus cardiomyocytes, or to the presence of accessory proteins in cardiomyocytes that can redox-regulate the aforementioned cysteine(s). Our results indicate that the recombinant channel may have a slightly different redox state compared to the native protein, at least with respect to FKBP12.6 binding. Importantly, the redox sensitivity of the FKBP12.6 interaction with mutant RyR2 channels was very similar to wild-type, irrespective of redox treatment or channel activation status (Figure 2E, F \& Table 2). This suggests that whether or not RyR2 mutants display increased channel activity due to oxidative conditions compared to wild-type, it is unlikely to involve regulation by FKBP12.6.

In summary, we assessed the FKBP12.6 binding characteristics of recombinant wildtype and mutant RyR2 channels under basal and oxidising conditions. Our results are not 
consistent with the hypothesis that CPVT- and ARVD2-linked RyR2 mutations result in reduced affinity for the stabilising FKBP12.6 accessory protein.

\section{Acknowledgements}

This research was supported by British Heart Foundation grants PG05/063 \& PG05/077 and by European Commission STREP programme (CONTICA; LSHM-CT-2005-018802). We are grateful to Dr C George for providing the plasmid DNA for eGFP-RyR2/S2246L and eGFPRyR2/R4497C.

\section{Abbreviations}

ARVD2, arrhythmogenic right ventricular dysplasia type 2; CPVT, catecholaminergic polymorphic ventricular tachycardia; DTT, dithiothreitol; eGFP, enhanced green fluorescent protein; FKBP, FK506-binding protein; HEK, human embryonic kidney cells; IP, immunoprecipitation; PKA, cAMP-dependent protein kinase; RyR, ryanodine receptor; SR, sarcoplasmic reticulum; WT, wild-type. 


\section{References}

1 George, C., Jundi, H., Thomas, N., Fry, D. and Lai, F. (2007) Ryanodine receptors and ventricular arrhythmias: Emerging trends in mutations, mechanisms and therapies, $\mathrm{J}$ Mol Cell Cardiol 42, 34-50

2 Liu, N., Ruan, Y. and Priori, S. (2008) Catecholaminergic polymorphic ventricular tachycardia, Prog Cardiovasc Diseases 51, 23-30

3 Zissimopoulos, S. and Lai, F. (2007) in Calcium: a matter of life or death, vol. 41, pp. 287-342, Elsevier

4 Wehrens, X., Lenhart, S., Huang, F., Vest, J., Reiken, S., Mohler, P., Sun, J., Guatimosim, S., Song, L.-S., Rosemblit, N., D'Armiento, J., Napolitano, C., Memmi, M., Priori, S., Lederer, W. and Marks, A. (2003) FKBP12.6 deficiency and defective calcium release channel (ryanodine receptor) function linked to exercise-induced sudden cardiac death, Cell 113, 829-840

5 Wehrens, X., Lehnart, S., Reiken, S., Deng, S., Vest, J., Cervantes, D., Coromilas, J., Landry, D. and Marks, A. (2004) Protection from cardiac arrhythmia through ryanodine receptor-stabilizing protein calstabin2, Science 304, 292-296

6 Lehnart, S., Wehrens, X., Laitinen, P., Reiken, S., Deng, S., Cheng, Z., Landry, D., Kontula, K., Swan, H. and Marks, A. (2004) Sudden death in familial ventricular tachycardia associated with calcium release channel (ryanodine receptor) leak, Circulation 109, 3208-3214

7 Lehnart, S., Terrenoire, C., Reiken, S., Wehrens, X., Song, L., Tillman, E., Mancarella, S., Coromillas, J., Lederer, W., Kass, R. and Marks, A. (2006) Stabilization of cardiac ryanodine receptor prevents intracellular calcium leak and arrhythmias, Proc Natl Acad Sci USA 103, 7906-7910

8 George, C., Higgs, G. and Lai, F. (2003) Ryanodine receptor mutations associated with stress-induced ventricular tachycardia mediate increased calcium release in stimulated cardiomyocytes, Circ Res 93, 531-540

9 Jiang, D., Wang, R., Xiao, B., Kong, H., Hunt, D., Choi, P., Zhang, L. and Chen, S. (2005) Enhanced store overload-induced $\mathrm{Ca}^{2+}$ release and channel sensitivity to luminal $\mathrm{Ca}^{2+}$ activation are common defects of RyR2 mutations linked to ventricular tachycardia and sudden death, Circ Res 97, 1173-1181

10 Cerrone, M., Colombi, B., Santoro, M., Raffaele di Barletta, M., Scelsi, M., Villani, L., Napolitano, C. and Priori, S. (2005) Bidirectional ventricular tachycardia and fibrillation elicited in a knock-in mouse model carrier of a mutation in the cardiac ryanodine receptor, Circ Res 96, e77-e82

11 Liu, N., Colombi, B., Memmi, M., Zissimopoulos, S., Rizzi, N., Negri, S., Imbriani, M., Napolitano, C., Lai, F. and Priori, S. (2006) Arrhythmogenesis in catecholaminergic polymorphic ventricular tachycardia: insigths from a RyR2 R4496C knock-in mouse model, Circ Res 99, 292-298

12 Xiao, J., Tian, X., Jones, P., Bolstad, J., Kong, H., Wang, R., Zhang, L., Duff, H., Gillis, A., Fleischer, S., Kotlikoff, M., Copello, J. and Chen, S. (2007) Removal of FKBP12.6 does not alter the conductance and activation of the cardiac ryanodine receptor or the susceptibility to stress-induced ventricular arrhythmias, J Biol Chem 282, 34828-24838

13 Zissimopoulos, S., Docrat, N. and Lai, F. (2007) Redox sensitivity of the ryanodine receptor interaction with FK506-binding protein, J Biol Chem 282, 6976-6983

14 Tiso, N., Stephan, D., Nava, A., Bagattin, A., Devaney, J., Stanchi, F., Larderet, G., Brahmbhatt, B., Brown, K., Bauce, B., Muragio, M., Basso, C., Thiene, G., Danieli, G. and Rampazzo, A. (2001) Identification of mutations in the cardiac ryanodine receptor gene in families affected with arrhythmogenic right ventricular cardiomyopathy type 2 (ARVD2), Human Mol Genet 10, 189-194 
15 Priori, S., Napolitano, C., Tiso, N., Memmi, M., Vignati, G., Bloise, R., Sorrentino, V. and Danieli, G. (2001) Mutations in the cardiac ryanodine receptor gene (hRyR2) underlie catecholaminergic polymorphic ventricular tachycardia, Circulation 103, 196200

16 Thomas, L., George, C. and Lai, F. (2004) Functional heterogeneity of ryanodine receptor mutations associated with sudden cardiac death, Cardiovasc Res 64, 52-60

17 Reid, M. (2001) Plasticity in skeletal, cardiac, and smooth muscle: redox modulation of skeletal muscle contraction: what we know and what we don't, J Appl Physiol 90, 724-731

18 Dhalla, N., Temsah, R. and Netticadan, T. (2000) Role of oxidative stress in cardiovascular diseases, J Hypertens 18, 655-673

19 Singal, P., Khaper, N., Palace, V. and Kumar, D. (1998) The role of oxidative stress in the genesis of heart disease, Cardiovasc Res 40, 426-432

20 Tong, J., Du, G., Chen, S. and MacLennan, D. (1999) HEK293 cells possess a carbachol- and thapsigargin-sensitive intracellular $\mathrm{Ca}^{2+}$ store that is responsive to stopflow medium changes and insensitive to caffeine and ryanodine, Biochem J 343, 39-44

21 Rossi, D., Simeoni, I., Micheli, M., Bootman, M., Lipp, P., Allen, P. and Sorrentino, V. (2002) RyR1 and RyR3 isoforms provide distinct intracellular $\mathrm{Ca}^{2+}$ signals $\mathrm{n}$ HEK293 cells, J Cell Sci 115, 2497-2504

22 Gaburjakova, M., Gaburjakova, J., Reiken, S., Huang, F., Marx, S., Rosemblit, N. and Marks, A. (2001) FKBP12 binding modulates ryanodine receptor channel gating, J Biol Chem 276, 16931-16935

23 Zissimopoulos, S. and Lai, F. (2005) Interaction of FKBP12.6 with the cardiac ryanodine receptor C-terminal domain, J Biol Chem 280, 5475-5485

24 Kannankeril, P., Mitchell, B., Goonasekera, S., Chelu, M., Zhang, W., Sood, S., Kearney, D., Danila, C., De Biasi, M., Wehrens, X., Pautler, R., Roden, D., Taffet, G., Dirksen, R., Anderson, M. and Hamilton, S. (2006) Mice with the R176Q cardiac ryanodine receptor mutation exhibit catecholamine-induced ventricular tachycardia and cardiomyopathy, Proc Natl Acad Sci USA 103, 12179-12184 


\section{Figure Legends}

Figure 1

\section{Interaction of recombinant RyR2 channels with FKBP12.6.}

Solubilised HEK293 microsomes expressing wild-type (WT) or mutant (R176Q, S2246L, R4497C) RyR2 channels - normalised for RyR2 and total protein content as detailed in Methods - were incubated with in vitro synthesised, haemoglobin-free $\left[{ }^{35} \mathrm{~S}\right] \mathrm{FKBP} 12.6$ in the presence $(+)$ or absence $(-)$ of $20 \mu \mathrm{M}$ rapamycin, either under ambient conditions (A) or in the presence of $2 \mathrm{mM} \mathrm{MgCl}_{2}(\mathbf{B})$. RyR2 was immunoprecipitated with $\mathrm{Ab}^{1093}$ and the presence of co-precipitated $\left[{ }^{35}\right.$ S]FKBP12.6 was analysed by SDS-PAGE (15\% gels) and autoradiography. An aliquot of the TNT reaction, $1 \%$ of the volume processed in co-IP assays was included in the autoradiogram to serve as a molecular weight standard (TNT).

Western blot analysis (4\% SDS-PAGE gel) using RyR2 isoform-specific $\mathrm{Ab}^{1093}$ of immunoprecipitated wild-type and mutant RyR2 channels (C).

Quantitative densitometry analysis of co-immunoprecipitated ${ }^{35}$ S]FKBP12.6 under ambient conditions ( $\mathrm{n}=4)(\mathbf{D})$ or in the presence of $2 \mathrm{mM} \mathrm{MgCl}_{2}(\mathrm{n}=4)(\mathbf{E})$ with normalisation against wild-type RyR2. Data are plotted as mean value \pm standard error; $* p<0.001$, $\ddagger p<0.05$.

Figure 2

\section{Redox sensitive interaction of recombinant RyR2 channels with FKBP12.6.}

Solubilised HEK293 microsomes expressing wild-type (WT) or mutant (R176Q, S2246L, R4497C) RyR2 channels were treated with redox reagent (2mM DTT, $1 \mathrm{mM} \mathrm{H}_{2} \mathrm{O}_{2}$, $200 \mu \mathrm{M}$ diamide) for $30 \mathrm{~min}$ at room temperature, followed by incubation with in vitro synthesised, haemoglobin-free $\left[{ }^{35} \mathrm{~S}\right] \mathrm{FKBP} 12.6$, either under ambient conditions $(\mathbf{A}, \mathbf{B})$ or in the presence of $2 \mathrm{mM} \mathrm{MgCl} 2(\mathbf{C}, \mathbf{D})$. RyR2 was immunoprecipitated with $\mathrm{Ab}^{1093}$ and the presence of co-precipitated $\left[{ }^{35}\right.$ S]FKBP12.6 was analysed by SDS-PAGE (15\% gels) and autoradiography. An aliquot of the TNT reaction, $1 \%$ of the volume processed in co-IP assays was included in the autoradiogram to serve as a molecular weight standard (TNT).

Quantitative densitometry analysis of co-immunoprecipitated $\left[{ }^{35}\right.$ S]FKBP12.6 under ambient conditions ( $\mathrm{n}=5)(\mathbf{E})$ or in the presence of $2 \mathrm{mM} \mathrm{MgCl}_{2}(\mathrm{n}=6)(\mathbf{F})$ with normalisation against control (no redox treatment). Data are plotted as mean value \pm standard error; * $p<0.001, \ddagger p<0.05$. 
Figure 1
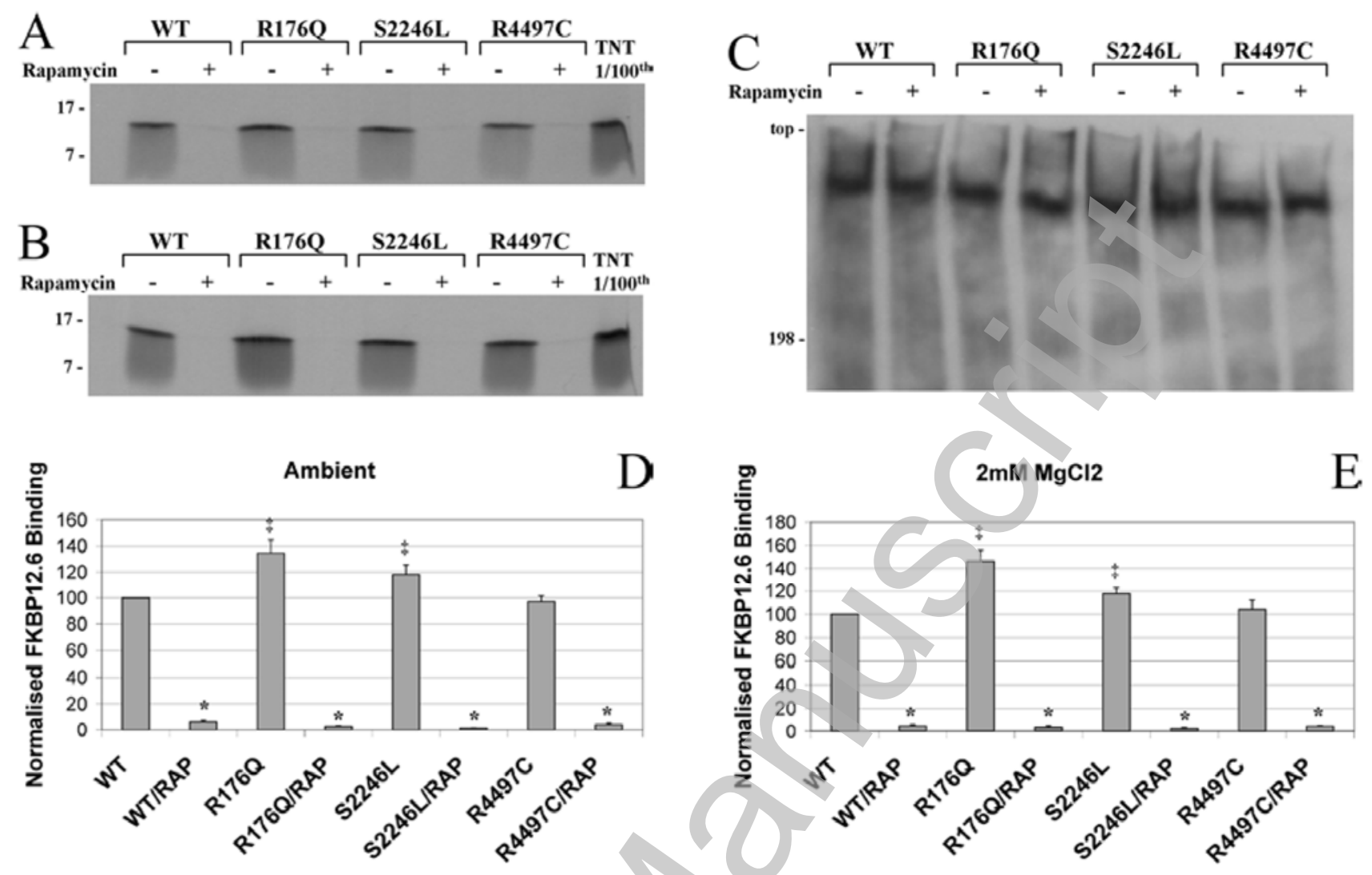

Licenced copy. Copying is not permitted, except with prior permission and as allowed by law. (C) 2009 The Authors Journal compilation (c) 2009 Portland Press Limited 
Figure 2
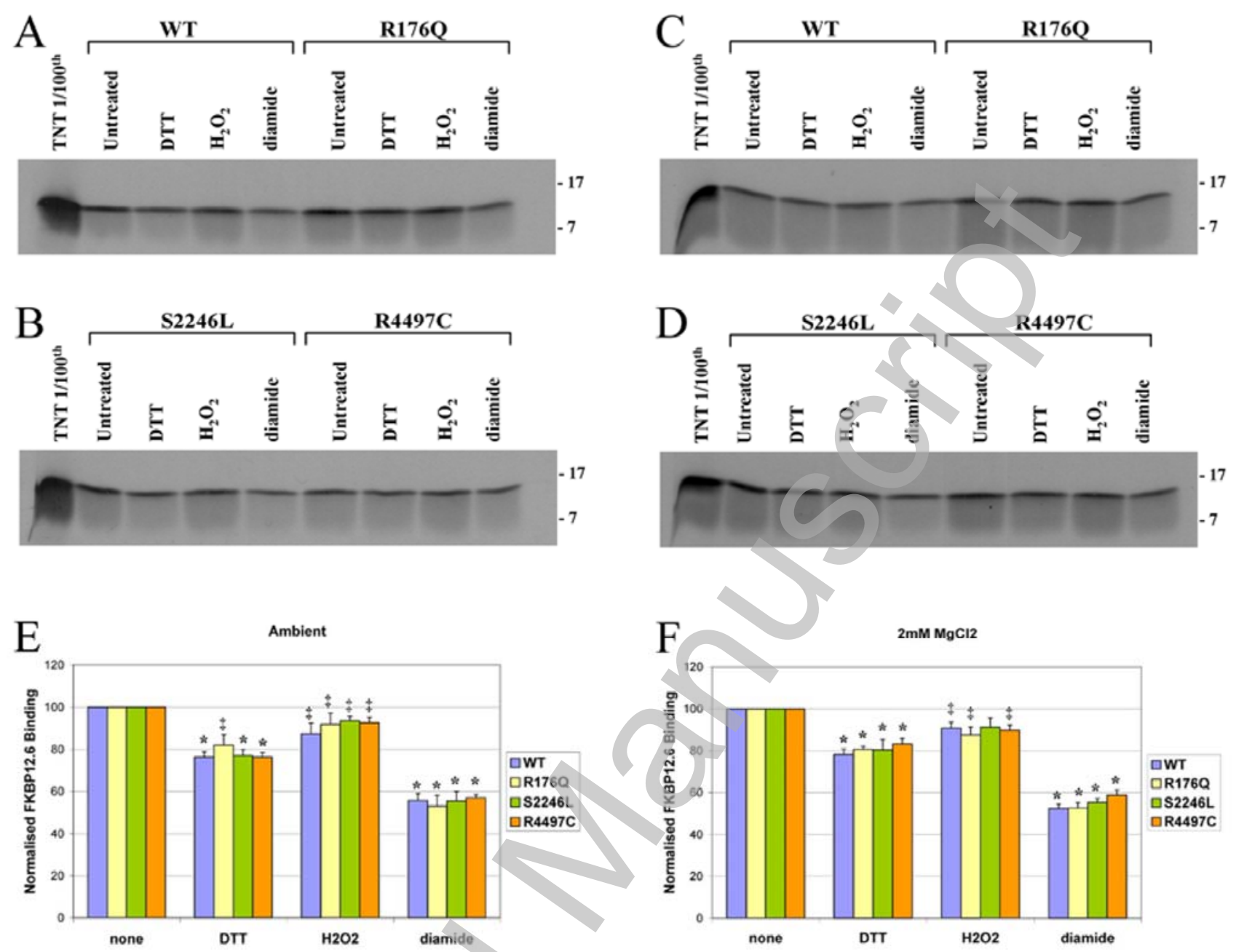

Licenced copy. Copying is not permitted, except with prior permission and as allowed by law. (C) 2009 The Authors Journal compilation (c) 2009 Portland Press Limited 


\section{Table Legends}

\section{Table 1}

Co-immunoprecipitation experiments to determine the FKBP12.6 binding affinity of recombinant wild-type and mutant RyR2 channels were carried out as described in the legend to Figure 1, followed by quantitation of the $\left[{ }^{35} \mathrm{~S}\right] \mathrm{FKBP} 12.6$ band by densitometric analysis of autoradiograms and normalisation against wild-type RyR2. The non-specific rapamycinresistant binding was subtracted from the total to obtain specific FKBP12.6 binding.

\section{Table 2}

Co-immunoprecipitation experiments to determine the redox sensitivity of the recombinant RyR2-FKBP12.6 interaction were carried out as described in the legend to Figure 2, followed by quantitation of the $\left[{ }^{35} \mathrm{~S}\right] \mathrm{FKBP} 12.6$ band by densitometric analysis of autoradiograms and normalisation against control (no redox treatment). 


\section{Tables}

\begin{tabular}{|c|c|c|c|c|}
\hline & WT & R176Q & S2246L & R4497C \\
\hline Ambient $(n=4)$ & 100 & $140.4 \pm 10.6$ & $124.6 \pm 6.5$ & $99.4 \pm 2.6$ \\
\hline $2 \mathrm{mM} \mathrm{MgCl} \mathrm{Mg}_{2}(\mathrm{n}=4)$ & 100 & $149.8 \pm 10.2$ & $121.1 \pm 4.4$ & $104.3 \pm 7.6$ \\
\hline
\end{tabular}

\begin{tabular}{|c|c|c|c|c|}
\hline Ambient $(n=5)$ & Control & DTT & $\overline{\mathbf{H}_{2} \mathbf{O}_{2}}$ & Diamide \\
\hline WT & 100 & $76.4 \pm 2.6$ & $87.5 \pm 5.0$ & $55.8 \pm 3.2$ \\
\hline R176Q & 100 & $82.0 \pm 5.0$ & $91.9 \pm 5.3$ & $53.0 \pm 5.1$ \\
\hline S2246L & 100 & $77.1 \pm 2.8$ & $93.6 \pm 2.0$ & $55.6 \pm 4.4$ \\
\hline R4497C & 100 & $76.4 \pm 2.1$ & $92.7 \pm 2.5$ & $57.0 \pm 1.4$ \\
\hline $2 \mathrm{mM} \mathrm{MgCl} 2(\mathrm{n}=6)$ & Control & DTT & $\mathrm{H}_{2} \mathrm{O}_{2}$ & Diamide \\
\hline WT & 100 & $78.2 \pm 2.6$ & $90.7 \pm 2.9$ & $52.4 \pm 2.1$ \\
\hline R176Q & 100 & $80.7 \pm 1.4$ & $87.6 \pm 3.8$ & $52.7 \pm 2.4$ \\
\hline S2246L & 100 & $80.4 \pm 5.0$ & $91.2 \pm 4.5$ & $55.3 \pm 1.8$ \\
\hline R4497C & 100 & $83.2 \pm 2.6$ & $89.8 \pm 2.4$ & $58.8 \pm 2.5$ \\
\hline
\end{tabular}

